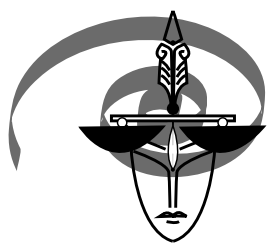

DOI: 10.1515/ep-2017-0007

Tuvya T. Amsel*

Tel Aviv

Israel

\title{
The Deceptive Human and the Detection of Deception**
}

Нечестный человек и детекции лжи

Key words: detection of deception, lie and deception

If The Bible is a genuine representative of mankind history than lying is as ancient as human mankind. Already in Chapter 3 of Genesis Adam and Eve try to conceal from God the fact that they had eaten from the forbidden tree. When asked by God where they are, Adam lies and answers "I was afraid, because I was naked: and I hid myself" [Genesis 3, 10]. It is the first known lie because neither was he naked nor was there a reason to hide.

The need to detect lies emerged with the advent of lying, which in return produced different techniques of detection. Old world suspects were subject to an array of horrendous ordeals using mostly fire and water alike. The idea behind the ordeals was that God will guide the truthful successfully through them.

*ta@amsel.co.il

** A chapter from the book Practical Polygraph soon to be published. 
Thousands years later the need to detect deception has not changed. Notice the term "detection of deception" rather than "detection of lies". The reason for using the first term rather than the latter is simple: a common practice among liars is deceiving rather than resorting to a straightforward lie, a practice already described in the book of Genesis when God asked Cain "Where is your brother Abel?" and Cain answered "Am I my brother's keeper?" [Genesis 4, 9].

\section{Deception amongst animals}

It seems that deception is not a unique trait among humans only, as animals exercise it too. Some types of deception in animals are completely involuntary but others are under voluntary control and may involve an element of learning. Most instances of voluntary deception in animals involve a simple behaviour, such as a cat arching its back and puffs up its hair on the neck, to appear larger when attacked. There are relatively few examples of animal behaviour which might be attributed to the manipulative type of deception which we know to occur in humans, i.e. "tactical deception". It has been argued that true deception assumes that (1) the deceiver knows that other animals have minds, (2) minds of different animals can believe different things to be true (when only one of these is actually true), and (3) it can make another mind believe that something false is actually true. True deception requires the deceiver to have the mental capacity to assess different representations of reality. Animal behaviour scientists are therefore wary of interpreting a single instance of behaviour as true deception, and explain it with simpler mental processes such as learned associations. In contrast, such human activities as military deception are certainly intentional, even when they involve such methods as camouflage, which are physically tantamount to methods animals use for camouflage [Wikipedia].

Mitchell and Thompson [1986] list four levels of deception in animals includes:

1. False markings on animals, such as butterfly markings that indicate their heads are at the back end of their bodies to help them escape; markings to make predators appear safe

2. False behaviour, such as a predator acting so as to hide its predatory nature while around the prey

3. Feigned injury to get or divert attention; for example, a parent bird feigning a broken wing to attract a predator away from its defenceless offspring

4. Verbal deception such as a chimp misleading other chimps to hide a food source, or a human lying in order to deceive another. 


\section{When does a human start to lie?}

According to a developmental psychology model of lying suggested by Talwar and Lee [2005] children around the age of two to three tell lies designed to conceal, yet fail to account for the mental state of the listener. Around the age of four, children learn to tell lies that are more plausible, and by the age of seven or eight also to tell lies which are more consistent with known facts and follow-up statements.

Lies told by toddlers are considered to be an important stage of development. Most toddlers think that their thoughts are transparent to the surroundings, and it is only lying that proves that they realise they are not,

\section{Why do children lie?}

Children lie for various reasons, with the most common being [Amsel 1994]:

- to avoid punishment or unpleasant consequences

- the conflict between gaining social status and the actual ability

- impossibility to adapt to the social behaviour

- the need to be in control

- imitation of adults

- to avoid confrontation

- victory of Id over Superego.

\section{The development of Moral Judgment}

The philosophical question whether humans are born good or bad, or as blank cards (tabula rasa) is well represented in the three main psychological approaches to human moral judgment i.e. honesty and integrity. According to the psychoanalytical theory postulated by Freud, humans are born bad i.e. all they want is to satisfy their needs and instincts, which in return pushes them to resort to lies as a means of achieving their needs. The cognitive theory proposed by Piaget explains that humans are born good but their life experience teaches them to lie. And the social learning theory maintains that men are born tabula rasa but their experience as toddlers and youngsters shape their behaviour making them either honest or dishonest adults.

\section{The effect of lies on human behaviour}

Lying is a complex process. Unlike the truth teller that just has to retrieve information from his memory, a liar has to cover up the true story, make up a convincing 
fictitious version, memorise it, cover up his fear of detection and so forth. All these put a mental burden on his mind, a burden that produces the deceptive cues and signs that we are looking for. Yet caution should be taken when looking for these cues; simply because lying per se does not produce any physical and/or psychological and/or behavioural cues or signs. What produces the cues are the emotions that accompany the lie.

There is a controversy between scientists as to which emotion or emotions generate the cues, but most believe that the fear of detection with the ensuing consequences is dominant here.

In addition, it should be emphasised that deceptive cues and signs are distinctive not only to deception. Each and every deception cue can be considered non-deceptive as well. For example, if someone avoids looking at the interviewer it does not necessarily mean that he is lying; it may as well be a cultural mannerism. Repeating different phrases that are considered deceptive might be a personal regular pattern of expression. For this reason, we should first establish the person's standard verbal and nonverbal manner and only once we did so can we start discussing the issue and look for deceptive cues deviating from the standard.

\section{Practicing lies}

What follows is a common case study of a theft in an office, the statement given by an alleged thief, and its analysis:

Fred's wallet, which was left on his office table, went missing. All of the employees that were present on the day and had access to the table where interviewed, including the employee who stole the wallet. When the thief heard the question: "Have you stolen Fred's wallet?" instead of answering "No." he replied: "As far as I recall I was so busy with the end-of-the-year report that I haven't even left my room; besides, I trust all the employees here, and I have no doubt that they are honest, and none of them is involved. It is either that Fred misplaced it and forgot about that or it must have been a messenger or a guest who visited the office. Besides, none of us will be lured by a mere 200. Anyway, ask around and everyone will tell you how many times I have returned missing objects to their owners."

Now, let's analyse the statement to have a better understanding of the liar's way of thinking: His opening statement, "As far as I recall", is a typical expression used by liars to avoid commitment. It comes in different shapes and includes "to the best of my knowledge", "unless I am mistaken", and similar phrases. They all, however, serve as an "emergency escape" in case he is confronted and told that he has been seen near 
the table, from which the wallet was stolen. In that case he can always back up and answer "I told you that it is 'as far as I recall'!"

The next expression: "I was so busy with the end-of-the-year report that I haven't even left my room" has the speaker remove himself from the scene of crime, thus making us assume that as he was not there he had no opportunity to steal the wallet. Similar expressions include "I don't know where Fred's desk is" and "I wasn't in the office when it happened".

He then proceeds to say "I trust all the employees here, and I have no doubt that they are honest, and none of them is involved. It is either that Fred misplaced it and forgot about that or it must have been a messenger or a guest who visited the office". What the speaker does now is to shift the suspicion from the office personnel and to speculate that either there was no theft at all or the fault lies with an anonymous person only visiting the office. By doing so he indirectly removes the suspicion from himself, as he is one of the office employees.

His next sentence: "Besides, none of us will be lured by a mere 200" is an indirect way of saying: "200 is too small amount for me" which can be translated into "I lack the motive to steal".

Last but definitely not least he says "Anyway, ask around and everyone will tell you how many times I have returned missing objects to their owners", and now he is pleading to be an honest person who does not have the right personality to steal. Similar expressions I have heard aplenty, include "I am a volunteer policeman" or "I am an orthodox religious person who follows God's commands to the iota".

An additional yet extremely important aspect of the analysis is what was not said. The thief did not bluntly deny the allegation. He did not answered "No." as innocent people do. Instead of giving us the short version, he baffles us up with his long and tedious statement. Analysing carefully his words, you find no denial of the allegation but rather statements that lead the listener to the conclusion that he denied the allegation, and therefore he is innocent. It is the listener's personal conclusion but not a denial, and that establishes the rule that says: if it was not said it never happened. Innocent suspects deny the allegation straightforwardly, without giving such long statements. The only exception to this rule is an unstructured interview yet, this rule is valid as long as you follow the structured interview. Moreover, the statement as a whole serves as a diversion.

These cues and signs are but tactical expressions of the deceptive strategy which is: keep the statement as logical as possible. 
The rationale behind this strategy is basic: people doubt illogical statements. Illogical statement raise doubt and disbelief, which in return raises lots of questions, and questions are the guilty person's mine field, one that the guilty desperately tries to avoid.

Please do not infer that innocent people do not make logical statements. But logic is the least concern of an innocent truthful teller. They just report what happened and they are not concerned with logic simply because they are not afraid of being asked questions - they have all the answers.

Because of this strategy, questioned guilty people commonly use such phrases as: "doesn't that make sense?" or "isn't it logical?". Like an interviewee describing an accident that he was involved in: "While driving I entered the junction and a vehicle that came from my left hit my door with its front part. As a result I was thrown forward, and hit the front windshield with my forehead". The puzzled interviewer asks: "Are you sure you were thrown forward? Because, if you got hit from the left side, you should have been thrown to your right and not forward." A truthful interviewee will think for a second, digesting the information, and then answer: "You know I never thought of it, you are absolutely right but this is exactly what happened". A deceptive respondent will by now have realised there is a logical flaw in his statement and will quickly formulate a new physics law of motion to be added to Newton's Laws, and answer along the lines: "Wrong. Wherever there is a combination of velocity and angle, objects move forward."

The liar's reason to deceive rather than tell a blatant lie is very practical: he does not know what type of information the interviewer possess so to avoid getting caught lying he must have an "emergency escape" should he be confronted with facts denying his statement.

\section{Practicing detection of deception}

The process described here is simple yet it takes training and more than that: a great deal of practice. Yet everyone can get there as long as they perform within the boundaries of the structured interview and if and only if they totally ignore their first impression as well as any bias and/or prejudice. As long as someone follows the detection rules and concentrates on the interviewee's words, their detection of deception will be accurate.

The rules are simple: open the discussion with small talk and establish what the speakers verbal and nonverbal norms are by looking for the deceptive cues and signs. 
If such a sign as avoiding eye contact comes up, ignore that sign when discussing the relevant issue. If it does not, look for it while discussing the relevant issue. Look for as many (at least ten) deceptive clues as possible surfacing when making a relevant statement.

Look for the following groups of deceptive sign and clues:

- Constant control

Reason: avoiding any slips of the tongue andlor suspicious moves

Result: unspontaneous behaviour

Examples:

in verbal communication

stalled answers or changing the subject

in nonverbal communication

verbal unsynchronized with nonverbal

- Guilty feelings

Reason: telling lies

Result: physical and psychological uneasiness

Examples:

in nonverbal communication

Breaking eye contact

Excessive movements

- Persuasion

Reason: argument in favour of the deceptive version

Result: using various persuasive phrases

Examples:

in verbal communication

"I have no reason to do it" (lack of motivation)

"I have never been investigated before"

"I am an honest person"

"I swear to you... on my kids।The Bibleletc.

"To tell you the truth"

"I was not in the neighbourhood" (opportunity)

"I have an alibi"

logical explanations

lack of feelings

over descriptive

in nonverbal communication

smile

laughter 
- Flattery

Reason: softening the investigator

Result: using various flattering phrases

Example:

in verbal communication

"What a lovely office"

"What a beautiful family"

"What an interesting work you have"

"Jo says hello"

"An excellent question"

- Stalling

super friendly

Reason: looking for the right answer

Result: delaying the answer to the question

Example:

in verbal communication

"Can you explain please"

"This reminds me of... " - changing the subject

"Please repeat the question"

repeating the question

not answering - silence or indirect answers

in verbal communication

biting lips

closed mouth

- Physical stimulation

Reason: tension, stress, anxiety

Result: physical stimulation

Example: verbal communication - over talkative

in nonverbal communication

scratching

accelerated pulse

perspiration

blushing

stuttering

- Attack

Reason: "offense is the best defence"

Result: aggressive behaviour

Example:

in verbal communication

"Your questions make me nervous" 
- Pity
"Don't you believe me?"
"It's very cold lhot here" - complaints
"What kind of questions are they?"
in nonverbal communication
pointing with fingers

Reason: softening the investigator

Result: emotional phrases

Example:

in verbal communication

reporting death \sickness $\mid$ problems

"Don't ask what I've been going through lately"

"They always blame me"

in nonverbal communication

- Evasive behaviour

faked weeping

Reason: avoiding the investigator andlor lying

Result: evasive phrases

Example:

in verbal communication

"I have no idea"

"I don't recall"

"I don't know"

does not commit himselflherself

in nonverbal communication

whistling

sitting on a part of the chair

standing aside

\section{Remarks about body language}

The clarity and significance of body language, or nonverbal communication as we call it, is exaggerated. Body language contains a great deal of clues about nervousness and uneasiness but very few deception cues and sign per se. Yet the lack of quantity is compensated by quality. Concentrate therefore on the words. that is what is called verbal communication cues, and listen carefully and attentively to every word spoken as well as unspoken, because sometimes what has not been said is very meaningful. 


\section{Words of caution:}

Some polygraph examiners consider the examinee's verbal and nonverbal deceptive clues and signs and the examinee's behavioural symptoms additional channels of information that help them to make the final decision. There are also some polygraph techniques to help that. This approach may, however, bias the examiner and her/ his decision making process to the point where instead of "believing the chart" the examiner "ignores the chart".

We do not factor the examinee's verbal and nonverbal behavioural clues and signs into our decision making process, nor do those clues serve us operationally in our decision making process. The only practical implementation of this practice is to:

- understand the deceptive individual's psychological state of mind

- in the pre-test - to assess the veracity of the examinee's answers to the comparison questions in order to evaluate the effectiveness of the question

- in the post-test - to assess the veracity of the examinee's explanations of why s/ he responded to the relevant questions and in return to decide whether an extra chart (with questions changes resulting from the explanation) is necessary or whether to start asking questions.

The verbal and nonverbal detection of deception can only be applied during the pretest interview and in the immediate post-test stage. In other words only when the examinee is not being confronted, and her/his version is not received in disbelief. Once the examiner displays disbelief and mistrust in the examinee's version, such a behaviour may have an effect on the examinee's behaviour to the point of distorting the analysis.

\section{References}

The Old Testament, The book of Genesis, 3 (10), King James version.

The Old Testament, The book of Genesis, 4 (9), King James version.

https://en.wikipedia.org/wiki/Deception_in_animals.

R.W. Mitchell, N.S. Thompson (1986), Deception, Perspectives on Human and Nonhuman Deceit, SUNY Press, 21-29.

V. Talwar, K. Lee (2008), Social and Cognitive Correlates of Children's Lying Behaviour, Child Development, 79 (4), 866-881.

T. Amsel (1994), The Truth about Lies, YTD Publisher, Tel Aviv, 31-36. 